\title{
ANALISIS STANDAR JUMLAH PERSONEL PENANGANAN \\ PENGANGKUTAN BARANG BERBAHAYA \\ DI BANDAR UDARA ADISUTJIPTO
}

\author{
Gunawan $^{1}$, Rully Medianto ${ }^{2}$ \\ Prodi Teknik Penerbangan \\ Sekolah Tinggi Teknologi Adisutjipto \\ Jalan Janti Blok R Lanud Adisutjipto, Yogyakarta \\ ${ }^{1}$ guns797@gmail.com
}

\begin{abstract}
Good and efficient Air cargo handling, especially for dangerous goods transportation need to be supported by licensed dangerous goods handling personnel and supported by the transport handling facilities as well as standard procedure. Comprehensive standards and procedures are required to reduce the risk of accidents caused by an error in the handling of the dangerous goods transportation. Main problems in this study: first, to analyse the process of air cargo transportation andling at the Adisutjipto Airport; second, to analyse the standard of the dangerous goods handling personel.

The cargo handling process consists of Outgoing (Acceptance, weighing, Dokumentation, Marking \& labeling, X-ray, Storage, Build-up, and Loading) and Incoming (Check Incoming Massage, Unloading, Breakdown, check lists, Physical Examination, Storage, Notice of Arrival, Delivered). The mathematical model of Dangerous Goods Handling Personnel Number Standard: DG Personel Cargo Agent Type A $=$ c.\% DG. (2,89x10-2), DG Personnel Warehousing Type $B=c \% \%$ DG $\left(4,53 \times 10^{-3}\right)$, DG Personnel Airline Type $B=c . \% D G .\left(4,89 \times 10^{-4}\right)$.
\end{abstract}

Keywords: Model, Standard, Personnel, Handling, Dangerous Goods

\section{Pendahuluan}

Dalam menghadapi kebijakan liberalisasi penerbangan (open sky) di kawasan ASEAN yang sudah berjalan sejak tahun 2015, Pemerintah c.q. Kementerian Perhubungan terus melakukan berbagai upaya dalam rangka meningkatkan daya saing nasional terhadap kebijakan tersebut. Kementerian Perhubungan sedang menyiapkan rute-rute penerbangan baru. Tidak kurang dari 130 rute tambahan sedang dikaji oleh Direktorat Jenderal Perhubungan Udara. Hal ini dapat berarti semakin meningkat pula jumlah manusia dan barang yang berpindah tempat menggunakan moda transportasi udara di masa yang akan datang. Dengan demikian menjadi tantangan tersendiri dilihat dari segi keamanan dan keselamatan penerbangan. Untuk menjawab tantangan tersebut, Kementerian Perhubungan telah membuat Program Keselamatan Penerbangan Sipil. 
Program Keselamatan Penerbangan Sipil perlu didukung oleh personel yang memiliki kompetensi dan sarana keselamatan penerbangan yang efektif dan tepat guna. Salah satu aspek yang mendukung keselamatan penerbangan adalah penanganan kargo udara. Saat ini perkembangan pengangkutan kargo udara sangat pesat, sehingga perlu penanganan yang baik dan efisien. Dengan perkembangan pengangkutan kargo udara khususnya pengangkutan barang berbahaya (dangerous goods) perlu diimbangi oleh pelayanan yang prima sebagaimana pelayanan yang dilakukan terhadap penumpang pesawat udara.

Penanganan kargo udara yang baik dan efisien khususnya untuk barang berbahaya perlu didukung oleh personel penanganan pengangkutan barang berbahaya yang berlisensi sebagai tanda bukti kompetensi yang dimiliki dan ditunjang oleh fasilitas penanganan pengangkutannya serta standar prosedur. Untuk mengurangi resiko kecelakaan yang diakibatkan oleh adanya kesalahan dalam penanganan pengangkutan barang berbahaya diperlukan standar dan prosedur yang komprehensif dan sesuai regulasi internasional.

Mengacu pada Undang-Undang Nomor 1 Tahun 2009 Pasal 136, "pengangkutan barang khusus dan berbahaya wajib memenuhi persyaratan keselamatan dan keamanan penerbangan". Untuk itu Badan Usaha yang menangani dan/atau mengangkut barang berbahaya wajib memperhatikan pelayanan pengangkutan dengan berpedoman kepada peraturan yang berlaku.

Berdasarkan uraian tersebut di atas perlu melakukan "Analisis Penanganan Pengangkutan Kargo Udara dan Penentuan Standar Jumlah Personel Penanganan Pengangkutan Barang Berbahaya di Bandar Udara Adisutjipto" guna merumuskan penyusunan standarisasi kebutuhan personel penanganan barang berbahaya, guna memenuhi aspek keselamatan dan keamanan penerbangan.

\section{Landasan Teori}

Barang berbahaya berdasarkan definisi ICAO adalah sebagai berikut : barang atau bahan yang dapat menyebabkan risiko terkait kesehatan, keselamatan, bangunan atau lingkungan sekitar, serta terdaftar pada daftar barang berbahaya dalam Technical Instruction (ICAO Doc 9284) atau termasuk dalam klasifikasi sesuai Technical Instruction tersebut.

Pengangkutan barang berbahaya menggunakan pesawat udara harus mengikuti ketentuan yang telah berlaku.Ketentuan secara teknisdapat mengikuti ketentuan yang telah dikeluarkan ICAO dan IATA, yaitu ICAO Doc. 9284 Technical Instruction for The Safe Transport of Dangerous Goods By Air (2009-2010 edition) dan IATA Dangerous Goods Regulations 2013 (54 $4^{\text {th }}$ edition). 
Secara garis besar kedua dokumen di atas menerapkan standar yang sama, dimana pada dokumen IATA sedikit lebih ketat lagi pengaturannya.

Personel yang dapat menangani pengangkutan barang berbahaya pada pesawat udara (menurut IATA) adalah sebagai berikut :

1. Shipper

2. Packers

3. Cargo agent/freight forwarder staff

4. Operator (Airline)

5. Ground handling staff

6. Passenger Handling staff

7. Flight crew members dan load planners

8. Security staff yang menangani prosedur screening terhadap barang bawaan penumpang, kargo dan pos.

\section{Metodologi Penelitian}

Untuk mempermudah proses penelitian, maka diperlukan suatu tahapan proses penelitian, yang digambarkan dalam Gambar 1, sebagai berikut:

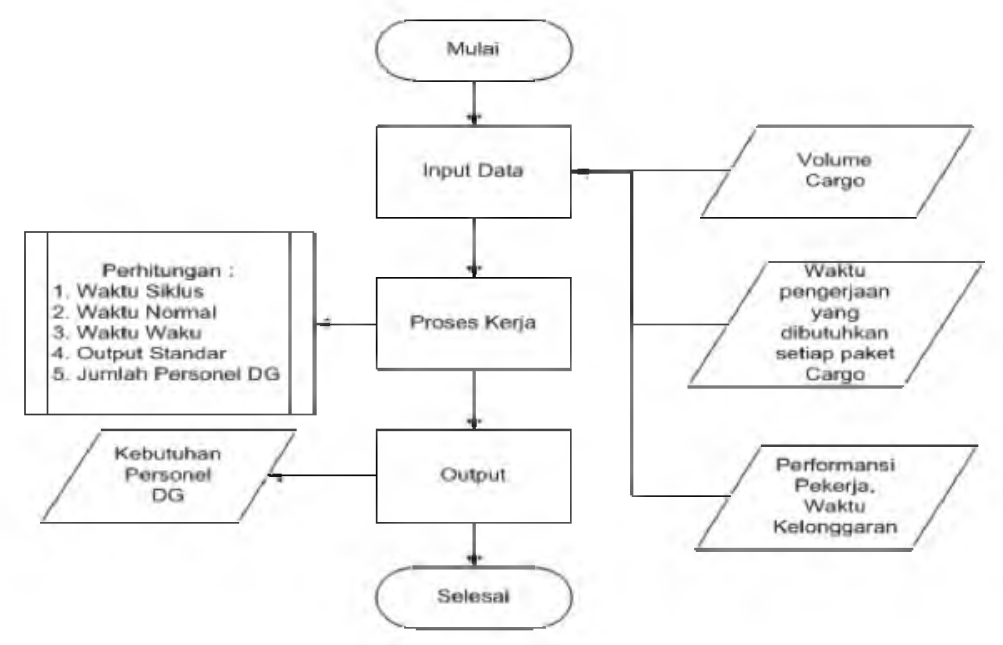

Gambar 1. Pengembangan Model Perhitungan Kebutuhan Personel

Model perhitungan yang dimaksud di dalam penelitian ini adalah model matematika umum yang dapat digunakan untuk menghitung kebutuhan personel barang berbahaya yang terdapat di bandar udara. Input model perhitungan ini adalah sebagai berikut :

a. Volume kargo dan volume barang berbahaya beserta jenisnya yang terdapat di bandar udara tersebut (data ini diperlukan untuk menentukan permintaan yang ada di bandar udara tersebut) 
b. Kelas bandar udara (data ini diperlukan untuk melihat kualitas fasilitas bandar udara secara umum)

c. Jumlah jam kerja yang diperlukan untuk menangani setiap paket pekerjaan barang berbahaya (data ini diperoleh dengan cara melakukan pengukuran langsung di lapangan).

d. Batasan jam kerja setiap personil berdasarkan ketentuan atau acuan perundangan/peraturan yang berlaku.

e. Jumlah dan jenis peralatan yang tersedia di dalam bandar udara untuk menangani barang berbahaya.

Proses yang akan dilakukan saat membuat model perhitungan ini sebagai berikut :

a. Mengelompokan barang berbahaya ke dalam kriteria - kriteria khusus

b. Mengidentifikasi jenis pekerjaan apa saja yang akan dilakukan untuk menangani barang berbahaya tersebut. Jenis pekerjaan tersebut akan berpengaruh terhadap waktu yang dibutuhkan untuk menangani barang berbahaya yang ada.

c. Menghitung volume barang berbahaya/ tahun untuk setiap kelompok barang yang ditentukan.

d. Menghitung kebutuhan waktu (dalam satuan jam) untuk menangani volume dari setiap kelompok barang berbahaya yang ada.

e. Menghitung jumlah seluruh waktu yang dibutuhkan untuk menangani barang berbahaya untuk semua kelompok barang berbahaya.

f. Menghitung jumlah personil yang dibutuhkan dengan cara membagi jumlah seluruh waktu penanganan dengan jumlah waktu efektif per orang/tahun

\section{Hasil dan Pembahasan}

\subsection{Proses Pelayanan Kargo Bandar Udara Internasional Adisutjipto}

Proses pelayanan kargo di Bandar udara terdiri dari 2 proses yaitu pelayanan kargo keluar (outgoing) dan pelayanan kargo masuk (incoming), selengkapnya sebagai berikut :

a. Untuk penanganan cargo outgoing (Gambar 2)

b. Untuk penanganan cargo incoming (Gambar 3)

Dalam pelayanan Kargo di Bandar udara Internasional Adisutjipto dilakukan oleh 3 (tiga) institusi dengan proses pertama dimulai dari agen kargo yang berupa proses penerimaan (acceptance), dokumentasi, pembungkusan (packing) dan pemberian tanda dan label marking labeling. Tahapan kedua adalah di gudang (warehouse) dimana terdapat proses X-ray, penyimpanan (storage), penyiapan (build-up). Dan ketiga yaitu di maskapai 
(airline) dimana tahapan ini adalah proses terakhir yaitu pemuatan ke pesawat udara (loading to aircraft).

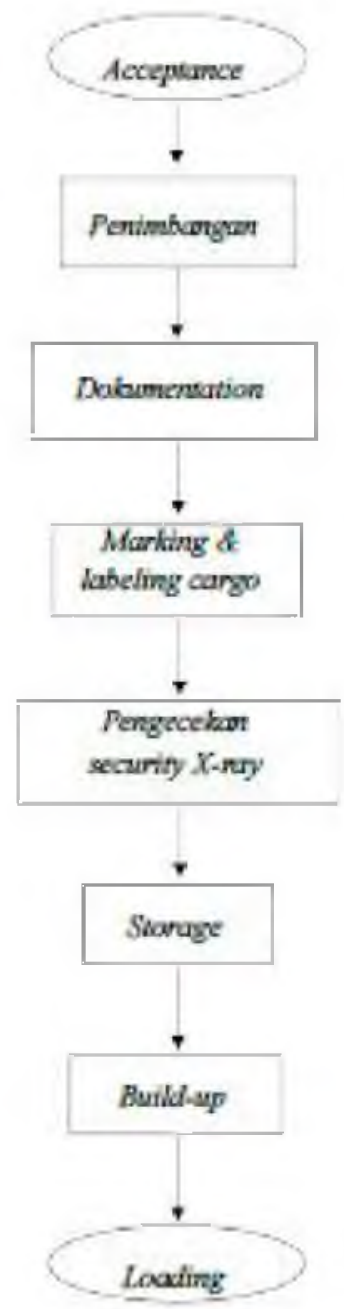

Gambar 2. Proses Pelayanan Outgoing Cargo Sumber: Standard Operating Procedure (SOP) Penanganan Cargo \& Mail Outgoing Nomor Dokument P- JOG-FF- 01 Revisi 08

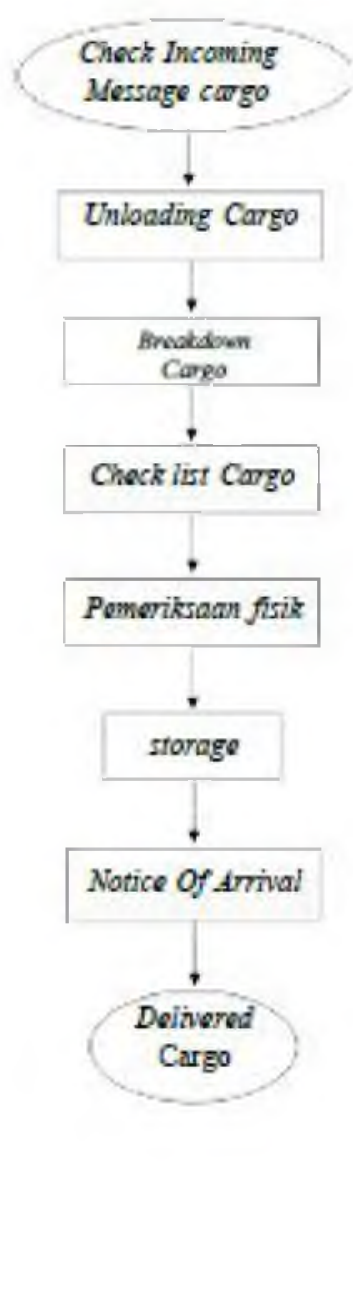

Gambar 3. Proses Pelayanan Incoming Cargo Sumber: Standard Operating Procedure (SOP) Penanganan Cargo \& Mail Incoming Nomor Dokument P-JOG-FF- 02 - Revisi 08 .

\subsection{Analisis Kebutuhan Personel Penanganan Barang Berbahaya Yang Diangkut Dengan Pesawat Udara}

Dalam melakukan perhitungan mengenai kebutuhan personel, metode yang digunakan adalah dengan menggunakan metode perhitungan kebutuhan berdasarkan beban kerja. Model perhitungan ini adalah model matematika umum yang dapat digunakan untuk menghitung kebutuhan personel barang berbahaya yang terdapat di bandar udara. Input model perhitungan ini adalah sebagai berikut : 
a. Volume kargo dan volume barang berbahaya beserta jenisnya yang terdapat di bandar udara tersebut (data ini diperlukan untuk menentukan demand yang ada di bandar udara tersebut)

b. Jumlah jam kerja yang diperlukan untuk menangani setiap paket pekerjaan barang berbahaya (data ini diperoleh dengan cara melakukan pengukuran langsung di lapangan).

c. Jumlah jam kerja efektif dari masing-masing personel

d. Jumlah dan jenis peralatan yang tersedia di dalam bandar udara untuk menangani barang berbahaya.

Proses yang akan dilakukan saat membuat model perhitunganadalah sebagai berikut:

a. Mengelompokan barang berbahaya ke dalam kriteria - kriteria khusus

b. Menghitung volume barang berbahaya/tahun untuk setiap kelompok barang yang ditentukan.

c. Menghitung kebutuhan waktu (dalam satuan menit) untuk menangani volume dari setiap kelompok barang berbahaya yang ada.

d. Menghitung jumlah seluruh waktu yang dibutuhkan untuk menangani barang berbahaya untuk semua kelompok barang berbahaya.

e. Menghitung jumlah personel yang dibutuhkan dengan cara membagi jumlah seluruh kargo dengan standar output Regulated Agent ataupun Warehouse.

\subsubsection{Pengukuran Waktu Kerja Penanganan Barang Berbahaya}

Rekapitulasi dari waktu rata-rata proses pelayanan kargo \& surat di PT. Gapura Angkasa Cabang Bandar Udara Internasional Adisutjipto adalah:

Tabel 1. Rekapitulasi waktu rata-rata penanganan barang berbahaya

\begin{tabular}{|c|c|c|}
\hline Institusi & Proses pelayanan & Waktu siklus (Menit) \\
\hline \multirow{4}{*}{ Cargo Agent } & Acceptance & 8,93 \\
\cline { 2 - 3 } & Packing & 9,64 \\
\cline { 2 - 3 } & Marking \& Labeling & 9,41 \\
\cline { 2 - 3 } Warehouse & Document & 10,16 \\
\cline { 2 - 3 } & X-ray & 1,67 \\
\cline { 2 - 3 } & Storage & 3,40 \\
\hline Airline & Build-up & 0,67 \\
\hline
\end{tabular}

\subsubsection{Pengolahan Data Waktu Kerja Penanganan Barang Berbahaya}

Berdasarkan alur Sederhana Penanganan Barang Berbahaya pada Cargo Agent, Warehouse dan Airline Output Standard dapat dihitung dan disajikan dalam tabel berikut: 
Analisis Standar Jumlah Personel Penanganan Pengangkutan Barang Berbahaya di Bandar Udara Adisutjipto

Tabel 2. Rekapitulasi output standar penanganan barang berbahaya

\begin{tabular}{|c|c|c|c|c|}
\hline Institusi & Proses pelayanan & Waktu Normal & Waktu Baku & Output Standard \\
\hline \multirow{4}{*}{ Cargo Agent } & Acceptance & 11,88 & 15,09 & 32 \\
\cline { 2 - 5 } & Packing & 12,82 & 16,28 & 29 \\
\cline { 2 - 5 } & Marking \& & 12,52 & 15,90 & 30 \\
\cline { 2 - 5 } & Document & 13,51 & 17,16 & 28 \\
\hline \multirow{3}{*}{ Warehouse } & X-ray & 2,22 & 2,92 & 164 \\
\cline { 2 - 5 } & Storage & 4,52 & 4,49 & 107 \\
\cline { 2 - 5 } & Build-up & 0,89 & 1,17 & 410 \\
\hline Airline & Loading & 0,82 & 1,08 & 444 \\
\hline
\end{tabular}

\subsubsection{Perhitungan Kebutuhan Personel Penanganan Barang Berbahaya}

Untuk menghitung personel DG (Dangerous Goods) perlu diketahui beberapa hal berikut ini :
a. Prosentase Kargo DG $10 \%$
b. Berat Kargo udara di Adisutjipto Tahun 2012 (c) $=12.850 .482 \mathrm{~kg}$
c. Rata-rata 1 Koli (k) = $25 \mathrm{~kg}$

d. Jumlah Hari Kerja Wajib efektif per Orang dalam 1 Tahun (t), dihitung seperti tabel berikut :

Tabel 3. Waktu efektif kerja setiap personel per tahun

\begin{tabular}{|c|c|c|}
\hline No & Uraian & Jumlah \\
\hline 1 & Jumlah hari kerja bandar udara per tahun. & 365 hari \\
\hline 2 & $\begin{array}{llll}\text { Ketentuan jam kerja wajib personel. } & & \\
\text { Undang-Undang } & \text { Nomor } \quad 13 & \text { Tahun2003 } & \text { tentang } \\
\text { Ketenagakerjaan } & & & \end{array}$ & 8 jam / hari \\
\hline 3 & $\begin{array}{l}\text { Jumlah Hari Libur Personel per Minggu Dalam } 1 \text { Tahun } \\
2 \text { hari x } 52 \text { Minggu }=104 \text { hari }\end{array}$ & 104 hari / tahun \\
\hline 4 & $\begin{array}{l}\text { Potensi hari tidak efektif } \\
\square \text { Cuti Tahunan }=12 \text { hari } \\
\square \text { Hari besar nasional }=14 \text { hari } \\
\square \text { Potensi libur pribadi (sakit, ijin,dsb.) }= \pm 4 \text { hari } \\
\square \text { Pendidikan dan pelatihan(peningkatan profesi) }= \pm 30 \text { hari }\end{array}$ & 60 hari / tahun \\
\hline 5 & $\begin{array}{l}\text { Hari kerja efektif per tahun } \\
365 \text { hari }-104 \text { hari }-60 \text { hari }=201 \text { hari }\end{array}$ & 201 hari/tahun \\
\hline 6 & $\begin{array}{l}\text { Hari kerja deduktif per tahun } \\
\square \text { Istirahat, makan }=305 \text { hari } \times 1 \text { jam } / \text { hari }=305 \text { jam } \\
=305 \text { jam } / 24 \mathrm{Jam} / \text { Hari }=12,7 \text { hari } \\
\square \text { Sholat }=305 \text { hari } \times 1 / 6 \text { jam } / \text { hari }=50,83 \text { jam } \\
=50.83 \text { jam } / 24 \mathrm{Jam} / \text { hari }=2,12 \text { hari }\end{array}$ & 14,82 hari/tahun \\
\hline 7 & $\begin{array}{l}\text { Hari kerja wajib efektif per personel per tahun } \\
201 \text { hari }-14,82 \text { hari }=186 \text { hari }\end{array}$ & 186 hari/tahun \\
\hline
\end{tabular}

Berat Kargo DG $(\mathrm{x}) \quad=\quad \cdot \% D G$ 


$$
\begin{aligned}
& =12.850 .482 \times 0,1 \\
& =1.285 .048 \mathrm{~kg}
\end{aligned}
$$

Jumlah Koli Kargo DG (KDG)

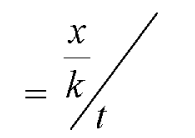

$$
\begin{aligned}
& \frac{1285048}{25} / 186 \\
= & 276,35 \approx 276 \text { Koli }
\end{aligned}
$$

\begin{tabular}{|c|c|c|c|c|c|c|c|c|}
\hline Institusi & Aktifitas & $\begin{array}{c}\text { Type } \\
\text { Lisence } \\
\text { Personel }\end{array}$ & $\begin{array}{c}\text { Output } \\
\text { Standar } \\
\text { (Koli/Orang) }\end{array}$ & $\begin{array}{l}\text { Kargo } \\
(\mathrm{Kg})\end{array}$ & $\begin{array}{c}\text { DG } 10 \% \\
\text { dari } \\
\text { Kargo } \\
(\mathrm{Kg}) \\
\end{array}$ & $\begin{array}{l}\text { KDG } \\
\text { (Koli) }\end{array}$ & $\begin{array}{l}\text { Jumlah } \\
\text { Personel }\end{array}$ & Total \\
\hline \multirow{4}{*}{ Cargo Agen } & Acceptance & $A$ & 32 & 12.850 .482 & 1.285 .048 & 276 & 9 & \multirow{4}{*}{37} \\
\hline & Packing & $A$ & 29 & 12.850 .482 & 1.285 .048 & 276 & 10 & \\
\hline & $\begin{array}{l}\text { Marking } \quad \& \\
\text { Labeling }\end{array}$ & A & 30 & 12.850 .482 & 1.285 .048 & 276 & 9 & \\
\hline & Documentation & A & 28 & 12.850 .482 & 1.285 .048 & 276 & 10 & \\
\hline \multirow{3}{*}{ Warehousing } & X-ray & $\mathrm{B}$ & 164 & 12.850 .482 & 1.285 .048 & 276 & 2 & \multirow{3}{*}{6} \\
\hline & Storage & $\mathrm{B}$ & 107 & 12.850 .482 & 1.285 .048 & 276 & 3 & \\
\hline & Build UP & B & 410 & 12.850 .482 & 1.285 .048 & 276 & 1 & \\
\hline Airline & Loading/Unloding & B & 444 & 12.850 .482 & 1.285 .048 & 276 & 1 & 1 \\
\hline \multicolumn{8}{|c|}{ Total Kebutuhan Personel DG } & 44 \\
\hline
\end{tabular}

Kebutuhan Personel DG Acceptance Cargo Agent

$$
\begin{aligned}
& =\frac{\mathrm{KDG}}{\text { Output Standar }} \\
& =\frac{276}{32} \\
& =8,63 \approx 9 \text { orang }
\end{aligned}
$$

Tabel 4. Contoh Penerapan Perhitungan Personel DG

\subsection{Model Standar Jumlah Personel Penanganan Barang Berbahaya Berdasarkan}

\section{Type Lisence Pada Cargo Agent, Warehousing dan Airline.}

Berdasarkan Tabel 4 contoh penerapan perhitungan personel DG dapat dimodelkan, sehingga didapatkan index dan model matematika (Rumus) untuk menghitung standar jumlah personel Penanganan Barang Berbahaya berdasarkan masing-masing Type Lisence Pada Cargo Agent, Warehousing dan Airline, seperti berikut :

$$
\begin{aligned}
& \mathrm{Ws}=\frac{\sum \mathrm{Xi}}{\mathrm{N}} \\
& \mathrm{Wn}=\mathrm{Ws} \times 1,33 \\
& \mathrm{~Wb}=\mathrm{Wn}+(\mathrm{Wn} \times 0,27)
\end{aligned}
$$




$$
\begin{aligned}
& =(\text { Ws } \times 1,33)+(\text { Ws } \times 1,33 \times 0,27) \\
& =W s \times 1,33 \times(1+0,27) \\
& =W s \times 1,33 \times 1,27 \\
& =W s \times 1,69
\end{aligned}
$$

$$
\begin{aligned}
& \text { Output Standar } \\
& \begin{aligned}
\mathrm{KDG} & =\frac{\pi / \mathrm{k}}{\mathrm{t}} \\
& =\frac{c \cdot \% \mathrm{DG} / 25}{186} \\
& =\frac{c . \% \mathrm{DG}}{4650} \\
& =\frac{\mathrm{c} \cdot \% \mathrm{DG}}{4650}
\end{aligned}
\end{aligned}
$$

$=\frac{\mathrm{KDG}}{\text { Output Standar }}$

$$
\begin{aligned}
& =\frac{\mathrm{c} . \% \mathrm{DG} / 4650}{480 / \mathrm{WS} \cdot 1,69} \\
& =\frac{\mathrm{c} \cdot \% \mathrm{DG} \cdot \mathrm{Ws} \cdot 1,69}{4650 \cdot(480)}
\end{aligned}
$$$$
=\frac{\mathrm{c} \cdot \% \mathrm{DG} \cdot \mathrm{Ws} \cdot 1,69}{2232000}
$$$$
=\text { c. } \% \text { DG.WS. }\left(7,57 \times 10^{-7}\right)
$$

Jika jumlah kargo dalam satuan ton, maka persamaan persamaan 6 menjadi :

Personel DG Cargo Agent Type Licence A =

$=\mathrm{c} \times \% \mathrm{DG} \times 8,93 \times\left(7,57 \times 10^{-7}\right) \times 1000$

$=\mathrm{c} \times \% \mathrm{DG} \times\left(6,67 \times 10^{-3}\right)$

\section{Keterangan :}

$\mathrm{c} \quad=$ Jumlah Kargo (ton)

$\% \mathrm{DG}=$ Prosentase $\mathrm{DG}$ 
Dengan cara yang sama model standar jumlah personel penanganan barang berbahaya berdasarkan Type Lisence pada Cargo Agent, Warehousing dan Airline dapat dibuat model matematika, selengkapnya model standar jumlah personel seperti berikut ini :

1. Personel DG Cargo Agent Type $A=c . \% D G .\left(2,89 \times 10^{-2}\right)$

2. Personel DG Warebousing Type $\mathrm{B}=c . \% D G\left(4,53 \times 10^{-3}\right)$

3. Personel DG Airline Type B $=$ c. $6 D G .\left(4,89 \times 10^{-4}\right)$

Penerapan model standar jumlah personel Penanganan Barang Berbahaya dapat dilakukan seperti berikut ini :

Tabel 5. Penerapan Standar Jumlah Personel DG

\begin{tabular}{|l|c|c|c|c|c|}
\hline & $\begin{array}{c}\text { Type } \\
\text { Lisence } \\
\text { Personel }\end{array}$ & Index & $\begin{array}{c}\text { Cargo } \\
(10 \%)\end{array}$ & $\begin{array}{c}\text { Udara per } \\
\text { Tahun } \\
\text { (Ton) }\end{array}$ & $\begin{array}{c}\text { Jumlah } \\
\text { Personel }\end{array}$ \\
\hline Cargo Agen & $\mathrm{A}$ & $2,89 \times 10^{-2}$ & 0,1 & 12850.428 & 37 \\
\hline Warehousing & $\mathrm{B}$ & $4,53 \times 10^{-3}$ & 0,1 & 12850.428 & 6 \\
\hline Airline & $\mathrm{B}$ & $4,89 \times 10^{-4}$ & 0,1 & 12850.428 & 1 \\
\hline
\end{tabular}

\section{Kesimpulan}

Berdasarkan dari pembahasan yang telah dilakukan, dapat disimpulkan sebagai berikut:

a. Proses penanganan kargo terdiri dari Outgoing (Acceptance, Penimbangan, Documentation, Marking \& labeling, X-ray, Storage, Build-up, dan Loading) dan Incoming ( Check Incoming Massage, Unloading, Breakdown, Check list, Pemeriksaan Fisik, Storage, Notice Of Arrival, Delivered)

b. Model Standar Jumlah Personel Penanganan Barang Berbahaya sebagai berikut :

1) Personel DG Cargo Agent Type $A=c . \% D G .\left(2,89 \times 10^{-2}\right)$

2) Personel DG Warehousing Type $\mathrm{B}=c .0 \mathrm{DG}\left(4,5,3 \times 10^{-9} \mathrm{y}\right.$

3) Personel DG Airline Type $B=c$. g $D G .\left(4,89 \times 10^{-4}\right)$ 
Daftar Pustaka

ANSI/ISEA Z87.1-2010, American National Standard: Occupational and Educational Personal Eye and Face Protection Devices.

Badan Standar Nasional, SNI 7079:2009 tentang Standar Nasional Indonesia (SNI) Sepatu Pengaman Dari Kulit Dengan Sol Poliuretan Dan Termoplastik Poliuretan Sistem Cetak Injeksi.

Barnes, Ralph. M, 1980, Motion and Time Study; Design and Measurement of Work, John Wiley \& Sons, New York.

Bureau Of Indian Standards, IS 15071 : 2002 Indian Standard : Chemical Protective Clothing-Specification.

Bureau Of Indian Standards, IS 15071 : 2002 Respiratory Protective Devices-HalfMasks And Quarter Masks-Specification.

IATA,2013, International Air Transport Association Dangerous Goods Regulation, 54th Edition, Effective January 1.

ICAO Annex 18, The Safe Transport Of Dangerous Goods by Air.

ICAO Doc. 9284 AN/905, Technical Instruction For The Safe Transport Of Dangerous Goods by Air.

ICAO Doc. 9375 AN/913 Dangerous Goods Training Manual.

ICAO Doc. 9481 AN/928, Emergency Response Guidance for Aircraft Incidents Involving Dangerous Goods.

ICAO Doc. 9859 - Safety Management Manual

Keputusan Direktur Jenderal Perhubungan Udara Nomor: SKEP/293/XI/99 Sertifikat Kecakapan Petugas Penanganan Pengangkutan Bahan Dan/Atau Barang Berbahaya Dengan Pesawat Udara.

Keputusan Menteri Tenaga Kerja Dan Transmigrasi Republik IndonesiaNomor Kep233/Men/2003 Tahun 2003 tentang Jenis dan Sifat Pekerjaan Yang Dijalankan Secara Terus Menerus.

National Fire Protection Association, NFPA 10 Standard for Portable Fire Extinguishers, Edition 2002.

Peraturan Direktorat Jenderal Perhubungan Udara Nomor KP 152 Tahun 2012 tentang Pengamanan Kargo dan Pos yang Diangkut dengan Pesawat Udara.

Peraturan Direktur Jenderal Perhubungan Udara Nomor: SKEP/275/II/2009 tentang Penanganan Dan Pengangkutan Bahan Dan/Atau Barang Berbahaya Dengan Pesawat Udara.

Peraturan Menteri Perhubungan Nomor : PM 31 Tahun 2013 Tentang Program Keamanan Penerbangan Nasional.

Peraturan Menteri Perhubungan Nomor : PM90 Tahun 2013 tentang Peraturan Keselamatan Penerbangan Sipil Bagian 92 tentang Pengangkutan Bahan dan/atau Barang Berbahaya Dengan Pesawat Udara.

Peraturan Menteri Perhubungan Nomor 60 Tahun 2010 tentang Organisasi dan tata kerja Departemen Perhubungan.

Peraturan Pemerintah No.3 Tahun 2001 tentang Keamanan Keselamatan Penerbangan (Lembaga Negara Tahun 2001 No.9, Tambahan Lembaran Negara No. 4075).

Sutalaksana, I. Z., R.A. Anggawisastra, dan Jann H. Tjaraatmajda, 1980, Teknik Tata Cara Kerja, Edisi Pertama, Departemen Teknik Industri ITB, Bandung.

Undang-Undang Nomor 1 Tahun 2009 tentang Penerbangan

Undang-Undang Nomor 13 Tahun 2003 tentang Ketenagakerjaan

Wignjosoebroto, Sritomo, Ergonomi, Study Gerak dan Waktu, Edisi Pertama, Penerbit PT Guna Widya, Surabaya, 2003. 
Gunawan, Rully Medianto 